\title{
Forced convection heat transfer of water/FMWCNT nanofluid in a microchannel with triangular ribs
}

\author{
Afshin Shiriny ${ }^{1} \cdot$ Morteza Bayareh $^{1} \cdot$ Afshin Ahmadi Nadooshan ${ }^{1} \cdot$ Dariush Bahrami $^{1}$
}

Received: 14 August 2019 / Accepted: 13 November 2019 / Published online: 18 November 2019

(c) Springer Nature Switzerland AG 2019

\begin{abstract}
In this study, forced convection heat transfer of water/FMWCNT nanofluid is studied inside a rectangular microchannel with triangular ribs on the lower wall numerically. The nanofluid flow is affected by a uniform magnetic field. The ribs have an insulating wall and a wall at a constant temperature. The other walls of the microchannel are insulated. Slip boundary condition is imposed on the walls and the temperature jump is ignored. The effect of different parameters such as Reynolds number, Hartmann number, slip coefficient and volume fraction of nanoparticles on the velocity and temperature distributions are investigated. The results are presented as the velocity and temperature profiles and local and average Nusselt numbers. The results demonstrate that the heat transfer rate and Nusselt number increase with the Reynolds number and the intensity of the magnetic field. Also, an enhancement in the volume fraction of nanoparticles and the slip coefficient leads to an increase in the heat transfer rate.
\end{abstract}

Keywords Microchannel · Triangular ribs · Forced convection · Nanofluid · Magnetic field · Slip velocity

\section{List of symbols}

$B \quad$ Dimensionless slip coefficient

$B_{0} \quad$ Magnetic field strength ( $\mathrm{T}$ )

$C_{p} \quad$ Specific heat $(\mathrm{J} / \mathrm{kg} \mathrm{K})$

$d \quad$ The height of ribs $(\mu \mathrm{m})$

$H$ Microchannel height $(\mu \mathrm{m})$

$\mathrm{Ha}$ Hartmann number

$L \quad$ Microchannel length $(\mu \mathrm{m})$

$\mathrm{Nu}$ Nusselt number

$\operatorname{Pr}$ Prandtl number

Re Reynolds number

$s \quad$ Distance between the ribs $(\mu \mathrm{m})$

$T \quad$ Temperature $(\mathrm{K})$

$u, v$ Velocity components $(\mathrm{m} / \mathrm{s})$

$u_{c} \quad$ Inlet nanofluid velocity $(\mathrm{m} / \mathrm{s})$

$u_{s} \quad$ Slip velocity of nanofluid $(\mathrm{m} / \mathrm{s})$

$w \quad$ Base length of the ribs $(\mu \mathrm{m})$

$x, y$ Coordinate axis $(\mu \mathrm{m})$

\author{
Greek symbols \\ $\beta \quad$ Slip coefficient ( $\mu \mathrm{m})$ \\ $\varphi \quad$ Volume fraction of nanoparticles \\ $\mu \quad$ Dynamic viscosity $\left(\mathrm{N} \mathrm{s} / \mathrm{m}^{2}\right)$ \\ $\theta \quad$ Dimensionless temperature \\ $\rho \quad$ Density $\left(\mathrm{kg} / \mathrm{m}^{3}\right)$ \\ $u \quad$ Kinematic viscosity $\left(\mathrm{m}^{2} / \mathrm{s}\right)$ \\ a Thermal diffusivity \\ Super- and sub-scripts \\ $f \quad$ Fluid \\ $m$ Mean value \\ nf Nanofluid
}

\section{Introduction}

In recent decades, microchannels have been used for heat rejection in various scientific and engineering applications, including medical applications, ink jet printers, and micro electromechanical devices [1,2]. On the other hand, the

Morteza Bayareh, m.bayareh@sku.ac.ir | 'Department of Mechanical Engineering, Shahrekord University, Shahrekord, Iran. 
use of nanofluids as a coolant fluid has recently become more of a concern for researchers due to the increase in the heat transfer and generation of uniform temperature and subsequently the reduction of thermal resistance. The addition of nanoparticles into the base fluid usually results in an increase in the viscosity. Akbarinia et al. [3] demonstrated that the viscosity increases with the volume fraction of nanoparticles $(\varphi)$. Several studies have shown that heat transfer increases with $\varphi$ and Reynolds number (Re) [4-11]. Also, it was reported that the Nusselt number $(\mathrm{Nu})$ increases by increasing the slip velocity $\left(u_{s}\right)$ on the microchannel walls [12-15]. In addition, the magnetic field can be applied to increase the heat transfer rate between the nanofluid and the microchannel walls. Previous studies revealed that as the magnetic field intensity increases, $u_{s}$ and Nu increase $[16,17]$. Sheikholeslami [17] studied the influence of nanoparticle shapes on convection heat transfer of $\mathrm{CuO} /$ water nanofluid under the effect of magnetic field. He demonstrated that Platelet-shaped nanoparticles lead to maximum heat transfer. Many researchers investigated the heat transfer rate of different nanofluids in various geometries in the absence or presence of external forces [18-22]. For example, Nikkhah et al. [18] evaluated the effect of oscillating heat flux and slip boundary conditions on forced convection heat transfer of water/ FMWCNT nanofluid. They revealed that $N u$ enhances with $\varphi, R e$, and slip coefficient. It can be concluded that heat transfer rate in a microchannel is a function of $\varphi$, $\operatorname{Re}$, slip coefficient and magnetic field.

On the other hand, flow disruption due to ribs, grooves, dimple surfaces, etc. results in an increase in the heat transfer through microchannels. Due to the high thermal efficiency, ribbed channels have a lot of applications in cross-flow heat exchangers, gas turbine, solar heaters and air-cooled nuclear reactors. Using the ribs on the inner surface of the heat exchangers leads to a reduction in thermal resistance and an increase in heat transfer. This is because of breaking the sub layer and creating local turbulent flow due to flow separation. Vanaki and Mohammed [23] studied forced convection of a nanofluid in a channel with different shapes of transverse ribs. Their results showed that performance evaluation criteria (PEC) is strongly influenced by the geometric parameters of the ribs. Safaei et al. [24] studied the laminar flow of water/copper nanofluid in a rectangular microchannel and demonstrated that the friction coefficient decreases with the slope of the ribs. Heydari et al. [25] evaluated the impact of attack angle of triangular ribs on heat transfer of water/Ag nanofluid and showed that as the angle of attack increases, heat transfer is improved. Shamsi et al. [26] studied the heat transfer of non-Newtonian water/CMC nanofluid in a rectangular microchannel with triangular ribs for different attack angles. Their results revealed that the average Nusselt number increases by $1.5 \%$ for $\operatorname{Re}=5$ and the attack angle of $30^{\circ}$. Shiriny et al. [27] showed that $\mathrm{Nu}$ and $u_{s}$ increase with the injection angle in a microchannel. Dewan and Sirvastava [28] reviewed the heat transfer enhancement in microchannels due to flow disruption caused by channel shape, ribs, grooves, porous mediums, etc. It is worth noting that grooves and ribs (baffles) are also used to enhance mixing efficiency in micromixers, for example the references [29-32].

In the present study, forced convection heat transfer of water/FMWCNT nanofluid is studied numerically inside a rectangular microchannel with triangular ribs under the influence of a magnetic field. The ribs have constant temperature surface and insulated one. The effects of various parameters such as Re, Hartman number $(\mathrm{Ha}), \varphi$ and slip coefficient on heat transfer are investigated.

\section{Problem statement}

A two-dimensional and horizontal rectangular microchannel $(L \times H)$ is considered as shown in Fig. 1. Water/ FMWCNT nanofluid with the velocity of $\mathrm{u}_{\mathrm{c}}$ and the temperature of $T_{c}=298 \mathrm{~K}$ enters the microchannel. On the lower wall of the microchannel, four triangular ribs with a height of $d=0.5 \mu \mathrm{m}$, width of $\mathrm{w}=0.5 \mu \mathrm{m}$ and the distance of $s=2.5 \mu \mathrm{m}$ are designed. One of the rib walls has constant temperature of $\mathrm{T}_{h}=303 \mathrm{~K}$ and the other one is insulated. The length between the microchannel inlet and the first rib is $L_{i}=10 \mu \mathrm{m}$. The length between the last rib and the channel outlet is $L_{o}=15.5 \mu \mathrm{m}$. The flow inside the microchannel is considered as laminar and steady due to low Reynolds numbers considered in the present study. The slip boundary condition is used for upper and lower walls of the microchannel. A uniform magnetic field with an intensity of $B_{o}$ is applied to the nanofluid flow. In this study, two different models $A$ and $B$ are considered for the arrangement of ribs (see Fig. 1). In addition, thermophysical properties of the nanofluid are presented in Table 1.

\section{Governing equations}

The governing equations for steady and laminar nanofluid flow inside a microchannel include continuity, momentum and energy equations and equations:

Continuity equation:

$\frac{\partial u}{\partial x}+\frac{\partial v}{\partial y}=0$

Momentum equation in the $x$-direction: 
$B_{0}$

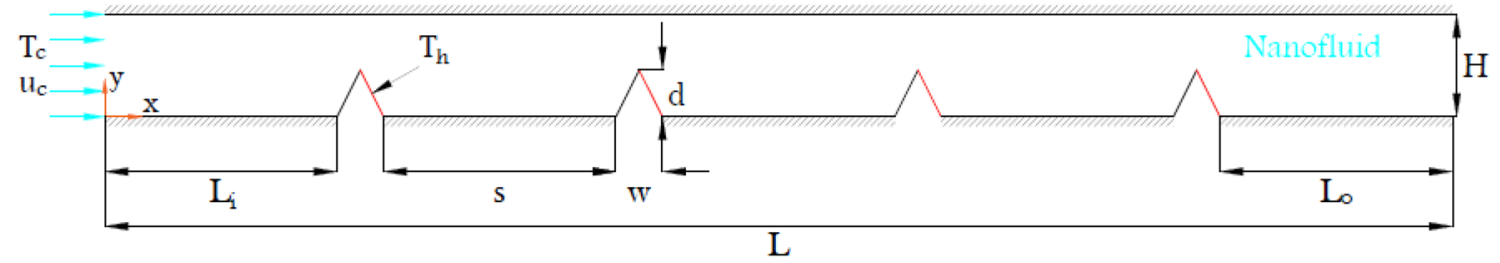

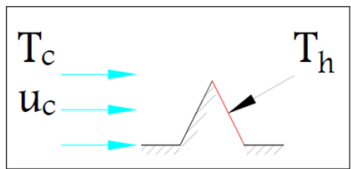

model A

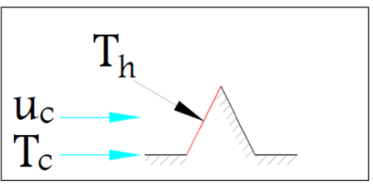

model B

Fig. 1 Schematic of the microchannel

Table 1 Thermophysical properties of water/FMWCNT nanofluid [16]

\begin{tabular}{llll}
\hline$\phi(\%)$ & $\rho_{\mathrm{nf}}\left(\mathrm{kg} / \mathrm{m}^{3}\right)$ & $\mu_{\mathrm{nf}}(\mathrm{Pa} \mathrm{s})$ & $\mathrm{k}_{\mathrm{nf}}(\mathrm{W} / \mathrm{m} \mathrm{K})$ \\
\hline 0 & 995.8 & $7.65 \times 10^{-4}$ & 0.62 \\
0.12 & 1003 & $7.80 \times 10^{-4}$ & 0.68 \\
0.25 & 1008 & $7.95 \times 10^{-4}$ & 0.75 \\
\hline
\end{tabular}

$u \frac{\partial u}{\partial x}+v \frac{\partial u}{\partial y}=-\frac{1}{\rho_{n f}} \frac{\partial p}{\partial x}+\vartheta_{n f}\left(\frac{\partial^{2} u}{\partial x^{2}}+\frac{\partial^{2} u}{\partial y^{2}}\right)-\frac{\sigma_{n f} B_{0}^{2}}{\rho_{n f}} u$

where $\sigma_{n f}=4.99 \times 10^{-2} \mathrm{~S} / \mathrm{cm}$ is electrical conductivity of nanofluid [16]. $B_{o}$ indicates the intensity of the magnetic field.

Momentum equation in the $y$-direction:

$v \frac{\partial v}{\partial x}+v \frac{\partial v}{\partial y}=-\frac{1}{\rho_{n f}} \frac{\partial p}{\partial y}+\vartheta_{n f}\left(\frac{\partial^{2} v}{\partial x^{2}}+\frac{\partial^{2} v}{\partial y^{2}}\right)$

Energy equation:

$u \frac{\partial T}{\partial x}+v \frac{\partial T}{\partial y}=\alpha_{n f}\left(\frac{\partial^{2} T}{\partial x^{2}}+\frac{\partial^{2} T}{\partial y^{2}}\right)$

Governing boundary conditions are as follows:

$u=u_{c}, v=0, T=T_{c} \quad$ For $x=0,0 \leq y \leq H$

$\frac{\partial u}{\partial x}=0, v=0, \frac{\partial \mathrm{T}}{\partial x}=0 \quad$ For $x=L, 0 \leq y \leq H$

$u=u_{s}, v=0, \frac{\partial T}{\partial y}=0 \quad$ For $0 \leq x \leq L, y=0$

$u=u_{s}, v=0, \frac{\partial T}{\partial y}=0 \quad$ For $0 \leq x \leq L, y=H$ where $u_{s}$ is slip velocity that is calculated using the following relation:

$u_{s}= \pm \beta\left(\frac{\partial u}{\partial y}\right)_{y=0, h}$

where $\beta$ is slip coefficient. The positive and negative signs are respectively related to the lower and upper walls of the microchannel.

By defining the following parameters, the above equations are non-dimensionalized:

$X=\frac{x}{h}, Y=\frac{y}{h}, U=\frac{u}{u_{i}}, V=\frac{v}{u_{i}}, H=\frac{h}{h}, L=\frac{l}{h}, B=\frac{\beta}{h}$
$\theta=\frac{T-T_{c}}{T_{h}-T_{c}}, P=\frac{p}{\rho_{n f} u_{i}^{2}}, R e=\frac{u_{i} h}{\vartheta_{n f}}, \operatorname{Pr}=\frac{\vartheta_{n f}}{\alpha_{n f}}, H a=B_{0} h\left(\frac{\sigma_{n f}}{\mu_{n f}}\right)^{0.5}$

Hence, the dimensionless governing equations are as follows:

$\frac{\partial U}{\partial X}+\frac{\partial V}{\partial Y}=0$

$U \frac{\partial U}{\partial X}+V \frac{\partial U}{\partial Y}=-\frac{\partial P}{\partial X}+\frac{\vartheta_{n f}}{\vartheta_{f} R e}\left(\frac{\partial^{2} U}{\partial X^{2}}+\frac{\partial^{2} U}{\partial Y^{2}}\right)-\frac{\rho_{f}}{\rho_{n f}} \frac{\sigma_{n f}}{\sigma_{n f}} \frac{H a^{2}}{R e} U$

$U \frac{\partial V}{\partial X}+V \frac{\partial V}{\partial Y}=-\frac{\partial P}{\partial Y}+\frac{\vartheta_{n f}}{\vartheta_{f} R e}\left(\frac{\partial^{2} V}{\partial X^{2}}+\frac{\partial^{2} V}{\partial Y^{2}}\right)$

$U \frac{\partial \theta}{\partial X}+Y \frac{\partial \theta}{\partial Y}=\frac{\alpha_{n f}}{\alpha_{f} \operatorname{Re} \cdot \operatorname{Pr}}\left(\frac{\partial^{2} \theta}{\partial X^{2}}+\frac{\partial^{2} \theta}{\partial Y^{2}}\right)$ 
where $\vec{F}=\vec{J} \times \vec{B}$ is the Lorentz force and $\vec{J}=\sigma_{n f}(\vec{E}+\vec{V} \times \vec{B})$ is induced electric current due to the electrical conductivity under the magnetic field. $\vec{V}$ is the velocity vector, $\vec{E}$ is the electric field, and $\vec{B}$ is the magnetic field. In this study, $\vec{E}$ is zero because of the absence of the external electric field.

In addition, non-dimensional governing boundary conditions are as follows:

$U=1, V=0, \theta=0 \quad$ For $X=0,0 \leq Y \leq 1$

$\frac{\partial U}{\partial X}=0, V=0, \frac{\partial \theta}{\partial X}=0 \quad$ For $X=\frac{L}{H}, 0 \leq Y \leq 1$

$U=U_{s}, V=0, \frac{\partial \theta}{\partial Y}=0 \quad$ For $0 \leq X \leq \frac{L}{H}, Y=0$

$U=U_{s}, V=0, \frac{\partial \theta}{\partial Y}=0 \quad$ For $0 \leq X \leq \frac{L}{H^{\prime}}, Y=1$

Dimensionless slip velocity is calculated as:

$U_{s}= \pm B\left(\frac{\partial U}{\partial Y}\right)_{Y=0,1}$

The density of nanofluid is obtained using the model proposed by Pak and Cho [33]:

$\rho_{n f}=(1-\phi) \rho_{f}+\phi \rho_{s}$

Thermal diffusion coefficient is calculated using the following relation:

$\alpha_{n f}=\frac{k_{n f}}{\left(\rho c_{p}\right)_{n f}}$

Buongiorno model is used to determine the specific heat of the nanofluid [34]:

$\left(\rho c_{p}\right)_{n f}=(1-\phi)\left(\rho c_{p}\right)_{f}+\phi\left(\rho c_{p}\right)_{s}$

To calculate the viscosity and effective thermal conductivity of the nanofluid, Brinkman model [35] and Chon model [16] are considered, respectively:

$\mu_{n f}=\frac{\mu_{f}}{(1-\phi)^{0.25}}$

$\frac{k_{n f}}{k_{f}}=1+64.7 \times \phi^{0.7460}\left(\frac{d_{f}}{d_{p}}\right)^{0.3690}\left(\frac{k_{s}}{k_{f}}\right)^{0.7476}\left(\frac{\mu}{\rho_{f} \alpha_{f}}\right)^{0.9955}\left(\frac{\rho_{f} B_{c} T}{3 \pi \mu^{2} I_{B F}}\right)^{1.2321}$
Electrical conductivity of the nanofluid is determined as follows:

$\frac{\sigma_{n f}}{\sigma_{f}}=1+\frac{3\left(\sigma_{s} / \sigma_{f}-1\right) \varphi}{\left(\sigma_{s} / \sigma_{f}+2\right)-\left(\sigma_{s} / \sigma_{f}-1\right) \varphi}$

And local Nusselt number $\left(\mathrm{Nu}_{\mathrm{x}}\right)$ and average Nusselt number $\left(\mathrm{Nu}_{\mathrm{m}}\right)$ are defined as follows, respectively:

$N u_{X}=-\frac{k_{n f}}{k_{f}}\left(\frac{\partial \theta}{\partial Y}\right)_{Y=1}$

$N u_{m}=\frac{1}{L} \int_{0}^{L} N u_{x} d X$

\section{Numerical method}

The governing equations are solved using finite volume method. The second order upwind scheme is employed for discretization. In addition, SIMPLEC algorithm is used for coupling the pressure and velocity fields. The criterion of the convergence is assumed to be less than $10^{-6}$ for the residuals.

\section{Grid study}

An unstructured grid is used to discretize the computational domain. Then, $\mathrm{Nu}_{\mathrm{m}}$ is calculated at $\mathrm{Re}=10$ for different grid resolutions as shown in Table 2 . The results for the grid resolutions of 30,100 and 100,000 are approximately the same, so the one with 30,100 grid points is selected for further simulations. It should be pointed out that the criterion to select the appropriate grid resolution is that the maximum error be less than $2 \%$ for $\mathrm{Nu}_{m}$.

\section{Validation}

To verify the present study, the present results are compared with those of Afrand et al. [16] who studied the effect of the magnetic field on forced convection heat transfer of water/ FMWNT nanofluid in a microchannel. The non-dimensional where $I_{B F}$ is free path of base fluid molecules, $B_{C}=1.3807 \times 10^{-23} \mathrm{~J} / \mathrm{K}$ is Boltzmann constant and $\mu$ is calculated using the following relation:

$\mu=A\left(10^{\frac{B}{T-C}}\right), C=140(\mathrm{~K}), B=247(\mathrm{~K}), A=2.414\left(10^{-5}\right)(\mathrm{Pa} \mathrm{s})$
Table $2 \mathrm{Nu}_{\mathrm{m}}$ for different grid resolutions

\begin{tabular}{llllll}
\hline Number of grid points & 2700 & 10,700 & 11,000 & 30,100 & 100,000 \\
\hline $\mathrm{Nu}_{\mathrm{m}}$ & 1.1869 & 1.2439 & 1.1445 & 1.4559 & 1.4576 \\
\hline
\end{tabular}




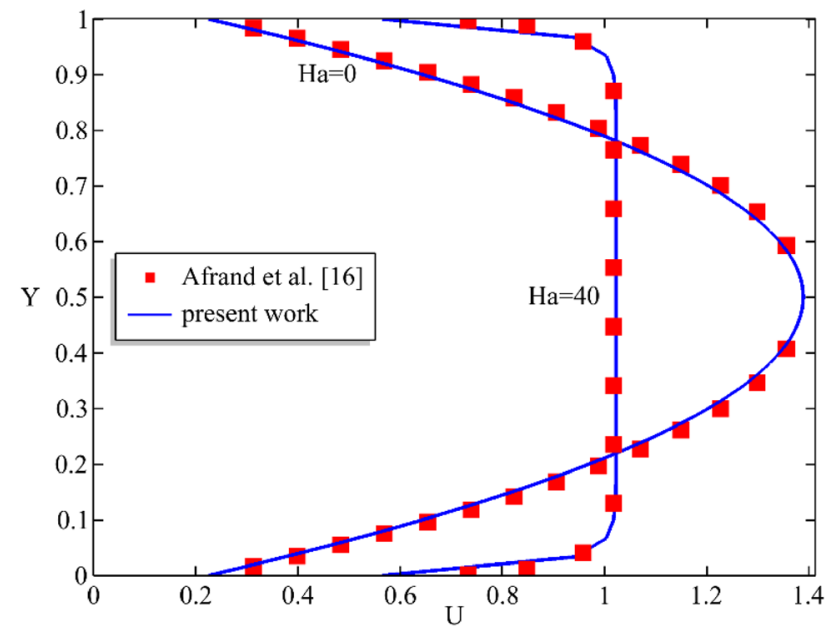

Fig. 2 Non-dimensional velocity profile in a microchannel for $\mathrm{Re}=20, \varphi=0.0025, \mathrm{~B}=0.005$ and $\mathrm{Ha}=0$ and $\mathrm{Ha}=40$

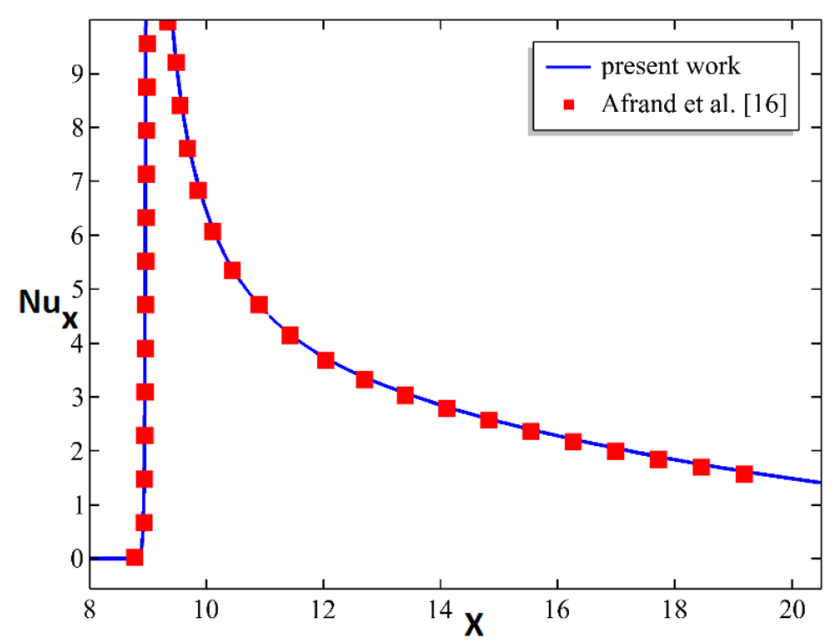

Fig. $3 \mathrm{Nu}_{\mathrm{x}}$ along the microchannel wall $\operatorname{Re}=20, \varphi=0.0025$, $\mathrm{B}=0.005$ and $\mathrm{Ha}=40$

velocity profile is plotted in Fig. 2 , where $\operatorname{Re}=20, \varphi=0.0025$, the slip coefficient $\mathrm{B}=0.005$ for $\mathrm{Ha}=0$ and $\mathrm{Ha}=40$. In addition, Fig. 3 illustrates the variations of $\mathrm{Nu}_{\mathrm{x}}$ along the microchannel wall for $\mathrm{Ha}=40$. The figures indicate that there are excellent agreement between the results obtained from the present simulations and those reported by Afrand et al. [16].

The present simulations are compared with the experimental results of Esmaili et al. [36] who investigated the influence of ribs on heat transfer rate in a microchannel experimentally (Fig. 4). This figure demonstrates that as Re enhances Nu increases. The present results are in very good agreement with experimental data.

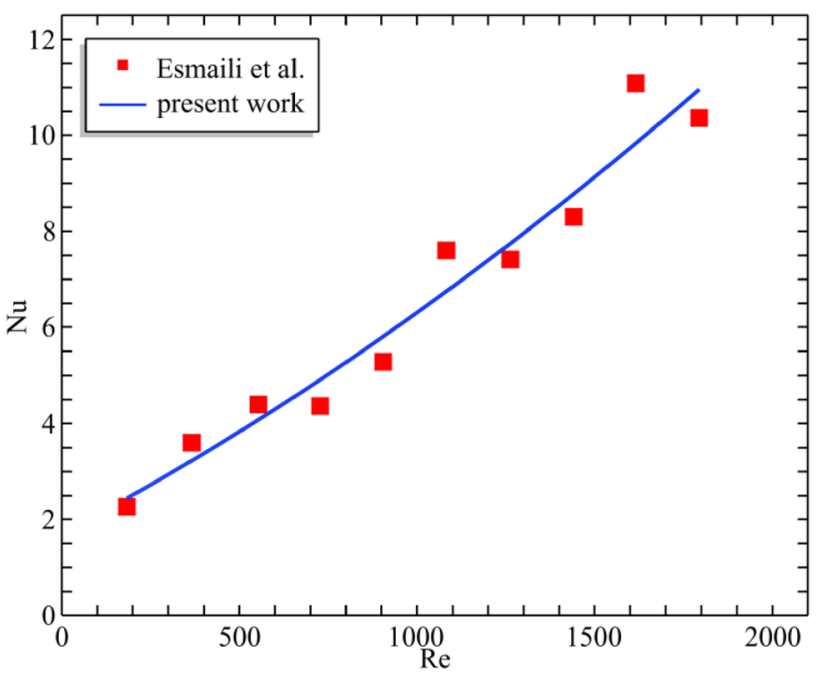

Fig. 4 Nu along the microchannel versus Re

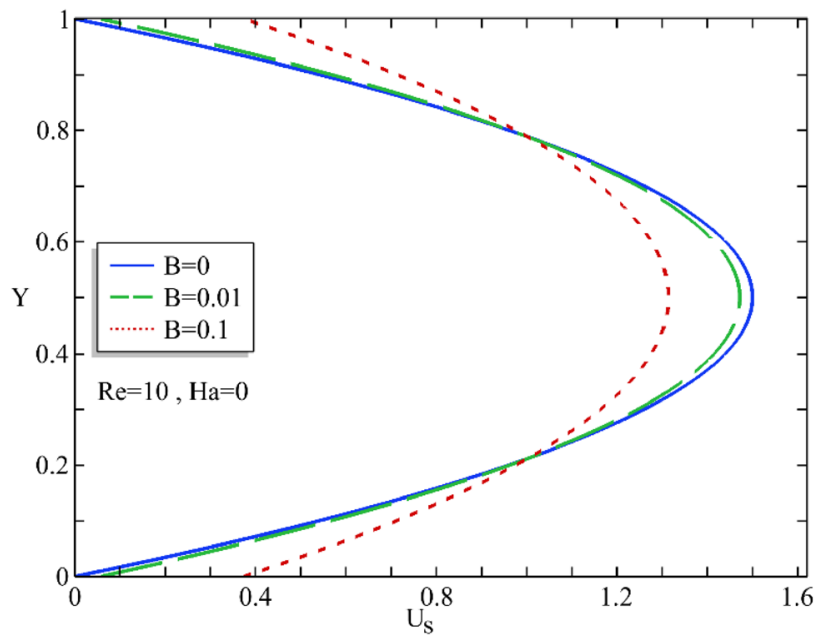

Fig. 5 Non-dimensional slip velocity for $\operatorname{Re}=10, \varphi=0, \mathrm{Ha}=0$ and different slip coefficients

\section{Results}

Forced convection heat transfer of water/FMWNT nanofluid in the rectangular microchannel shown in Fig. 1 is numerically investigated. The ribs involve a constant temperature surface and an isolated one. According to Fig. 1, two models are considered for the ribs: in model A, the nanofluid collides first with the insulated surface and in model $B$, it reaches first the surface with the temperature $T_{h}$. Effect of the magnetic field, Re, slip coefficient and $\varphi$ on the velocity and temperature fields and $\mathrm{Nu}$ are evaluated. 
Figure 5 shows the variations of $u_{s}$ on outlet cross-section of the microchannel in the absence of the magnetic field for $\varphi=0, \operatorname{Re}=10$ and different slip coefficients. The maximum velocity occurs at the center of the channel. It decreases with the slip coefficient due to an increase in $u_{s}$ on the microchannel walls. Based on the mass conservation law, as $u_{s}$ increases in the vicinity of the walls, the maximum velocity decreases at the channel center. By applying the magnetic field, the Lorentz force is exerted in the opposite direction of nanofluid flow, leading to an increase in the $u_{s}$ close to the walls of the microchannel due to a reduction in the nanofluid velocity at the channel center. Velocity distribution is plotted in Fig. 6 for $\varphi=0.0025, \operatorname{Re}=10, \mathrm{~B}=0.01$ and various values of $\mathrm{Ha}$. An increase in $\mathrm{Ha}$ leads to the formation of a uniform flow core from $Y \approx 0.15$ to $Y \approx 0.85$, indicating an increase in the nanofluid velocity in the vicinity of walls.

Figure 7 shows the variations in dimensionless slip velocity along the microchannel walls for $\mathrm{Re}=10, \mathrm{Ha}=0$, $\varphi=0$ and various slip coefficients. $u_{s}$ is maximum at the entrance, and then decreases with flow through the channel. As the flow passes through each rib, $u_{s}$ increases. After that it decreases when the nanofluid flow away from the ribs. This process continues until $u_{s}$ reaches a constant value at the microchannel outlet. Also, it is found that $u_{s}$ increases along the channel walls by increasing the slip coefficient.

By applying the magnetic field and generation of the Lorentz force in the opposite direction of the flow, $u_{s}$ increases at the microchannel walls (Fig. 8). $u_{s}$ on the lower wall decreases due to flow separation and formation of reverse flows behind the ribs. As Ha increases, $u_{s}$ increases.

Figure 9 displays the dimensionless velocity contour for different values of $\mathrm{Ha}$. It should be noted that only the

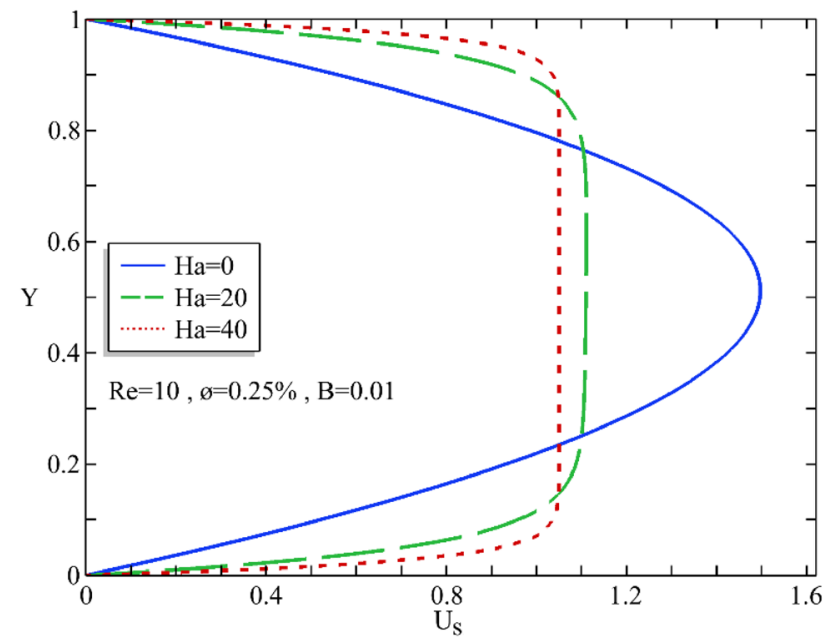

Fig. 6 Non-dimensional slip velocity for $\operatorname{Re}=10, \varphi=0.0025, B=0.01$ and different values of $\mathrm{Ha}$

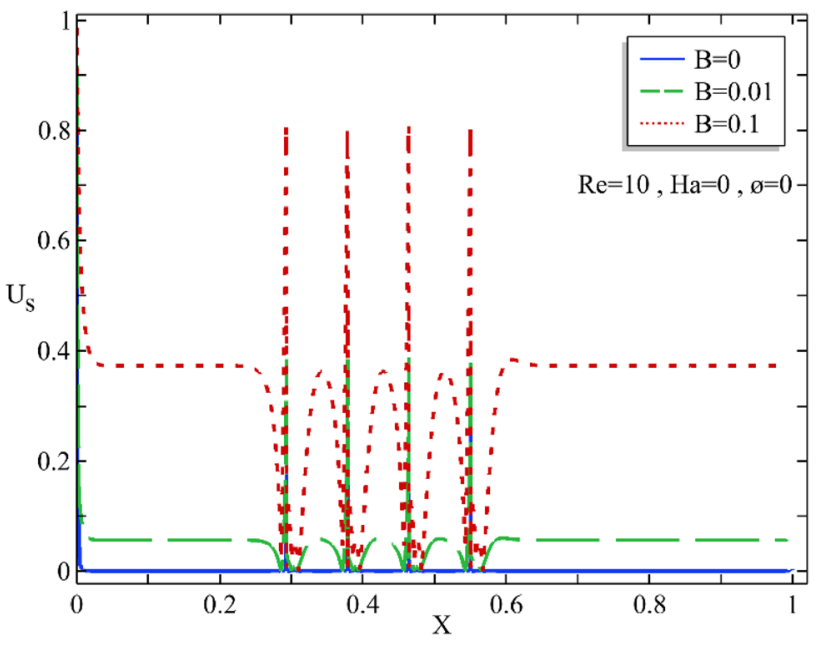

Fig. 7 Non-dimensional slip velocity along the microchannel for $\mathrm{Re}=10, \varphi=0, \mathrm{Ha}=0$ and different slip coefficients

contours around the third rib are provided for the clarity. As the intensity of the magnetic field decreases, the flow velocity on the central line of the microchannel and the density of streamlines in the area decrease. When the flow collides with the ribs, a vortical flow is generated at the rear of the ribs and the streamlines move towards the walls. It is observed that the vortical flow region between the ribs decreases by increasing $\mathrm{Ha}$ and increasing the velocity in the vicinity of the wall between the ribs. In other words, the vortex strength decreases and nanofluid flow remains more close to the ribs as $\mathrm{Ha}$ increases (Lorentz force increases).

In Fig. 10, the dimensionless temperature contours are shown around the first rib for $\operatorname{Re}=10, \varphi=0.0025, B=0.01$ and different values of $\mathrm{Ha}$. As can be seen, the thickness

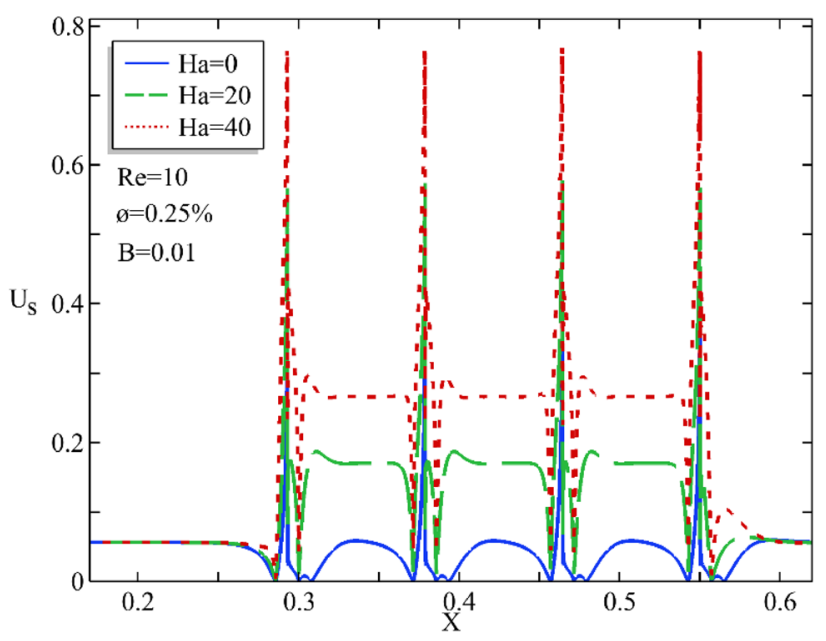

Fig. 8 Non-dimensional slip velocity along the microchannel for $\mathrm{Re}=10, \varnothing=0.0025, \mathrm{~B}=0.01$ and different values of $\mathrm{Ha}$ 


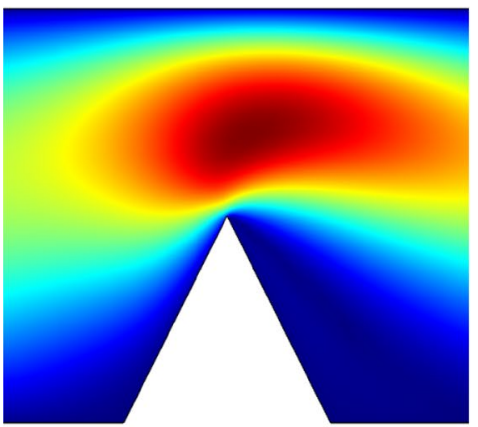

(a)

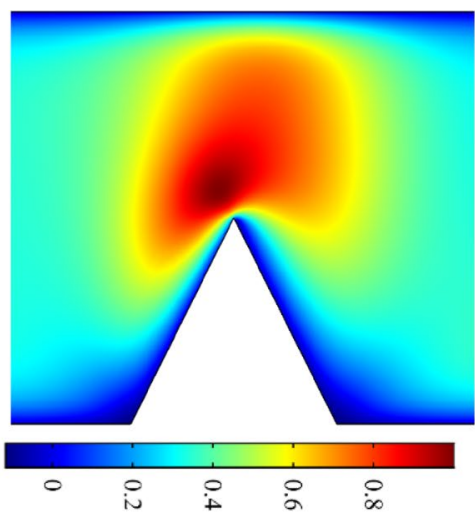

(b)

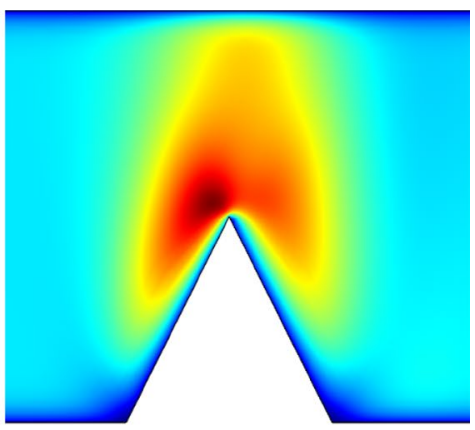

(c)

Fig. 9 Dimensionless velocity contours on the third rib for $\mathrm{Re}=10, \varphi=0.0025, \mathrm{~B}=0.01$ and: $\mathbf{a} \mathrm{Ha}=0, \mathbf{b} \mathrm{Ha}=20$, and $\mathbf{c H a}=40$

of the thermal boundary layer decreases and hence the heat transfer rate increases with the increase in the magnetic field intensity. As the Lorentz force increase, the nanofluid flow occupies more regions between the ribs, the vortical area becomes smaller and the nanofluid floe remains more in the vicinity of hot walls. Figure 11 reveals that an increase in Re results in a reduction in the thickness of thermal boundary layer, leading to an increase in the temperature gradient. Therefore, the heat transfer rate and $\mathrm{Nu}_{\mathrm{x}}$ increase. By passing the flow through the ribs and increasing the temperature gradient, $\mathrm{Nu}_{\mathrm{x}}$ increases. When the flow passes through the insulated walls of the channel, the heat transfer rate and $\mathrm{Nu}_{\mathrm{x}}$ tend to be zero. Heat transfer performance of two rib models is compared in Fig. 12 for $\operatorname{Re}=10, \varphi=0.0025$ and $B=0.01$ in the absence of magnetic field. The negative value of $\mathrm{Nu}_{x}$ for model $A$ is higher than that for model $\mathrm{B}$. Hence, the heat transfer rate is higher when model $A$ is used in comparison with the situation in which model $B$ is employed.

In Fig. 13, $\mathrm{Nu}_{\mathrm{m}}$ is shown in terms of the slip coefficient for $\mathrm{Ha}=0, \mathrm{Re}=10$ and various volume fractions of solid nanoparticles. It is demonstrated that $\mathrm{Nu}_{\mathrm{m}}$ between the nanofluid and constant temperature surface of ribs and higher temperature gradient. One of the important results obtained in this study is the difference between the slip coefficients for these two models. It is concluded that $\mathrm{Nu}_{m}$ decreases with slip coefficient for model A. However, it increases with the slip coefficient for model B. The reason can be explained as follows: as the slip coefficient and thus the fluid velocity on the surface increase, the flow separation occurs faster for the model A compared to the model $B$. In addition, an increase in the $\varphi$ leads to an enhancement of thermal conductivity. Thus, $\mathrm{Nu}_{\mathrm{m}}$ increases. This is valid for the models $A$ and $B$.

$\mathrm{Nu}_{m}$ versus $\mathrm{Ha}$ is plotted in Fig. 14 for $\mathrm{B}=0, \mathrm{Re}=10$ and various volume fractions of nanoparticles. As the magnetic force is applied, the Lorentz force is generated in the opposite direction of the nanofluid flow due to the electrical conductivity of nanoparticles and the base fluid, leading to a reduction in the nanofluid velocity. Thus, the nanofluid remains more in the vicinity of hot surfaces of the ribs, resulting in an increase in the heat transfer rate and $\mathrm{Nu}_{\mathrm{m}}$. As the nanofluid flows through the channel, it is heated and the temperature gradient decreases. Hence, the slope of $\mathrm{Nu}_{\mathrm{m}}$ diagram is reduced. Also, by comparing $\mathrm{Nu}_{\mathrm{m}}$ for the two models $A$ and $B$, it is concluded that when $\mathrm{Ha}$ increases, $\mathrm{Nu}_{\mathrm{m}}$ increases by the same slope approximately.

In Fig. 15, the variations of $\mathrm{Nu}_{\mathrm{m}}$ are plotted as a function of Re for various volume fractions of solid nanoparticles in the absence of magnetic fields and slip coefficient for two models $A$ and $B$. It is observed that the penetration of the streamlines increases behind the ribs by increasing $R e$ (increasing of the inertial force). Therefore, the vortical flows are strengthened, leading to a reduction in the thickness of the hydrodynamic and thermal boundary layers. As a result, the temperature gradient increases and heat transfer and $\mathrm{Nu}_{\mathrm{m}}$ increase. In the model $\mathrm{B}$, heat transfer is higher than model $A$ due to higher contact between hot surfaces and the nanofluid.

\section{Discussion}

Heat transfer mechanisms in microchannels are categorized as active or passive methods [37]. Active microdevices use external actuators such as magnetic field, electrical field, etc. to drive the fluid and enhance the heat transfer rate. Passive ones work based on their geometries [30, 31]. Grooved/ribbed surfaces are commonly employed in passive devices to improve the mixing rate, making the fluid flow to disturb and to improve the thermal performance. Forced convection heat transfer 
Fig. 10 Dimensionless temperature contours on the first rib for $\operatorname{Re}=10, \varphi=0.0025, B=0.01$ and: $\mathbf{a} \mathrm{Ha}=0, \mathbf{b} \mathrm{Ha}=20$, and $\mathbf{c}$ $\mathrm{Ha}=40$
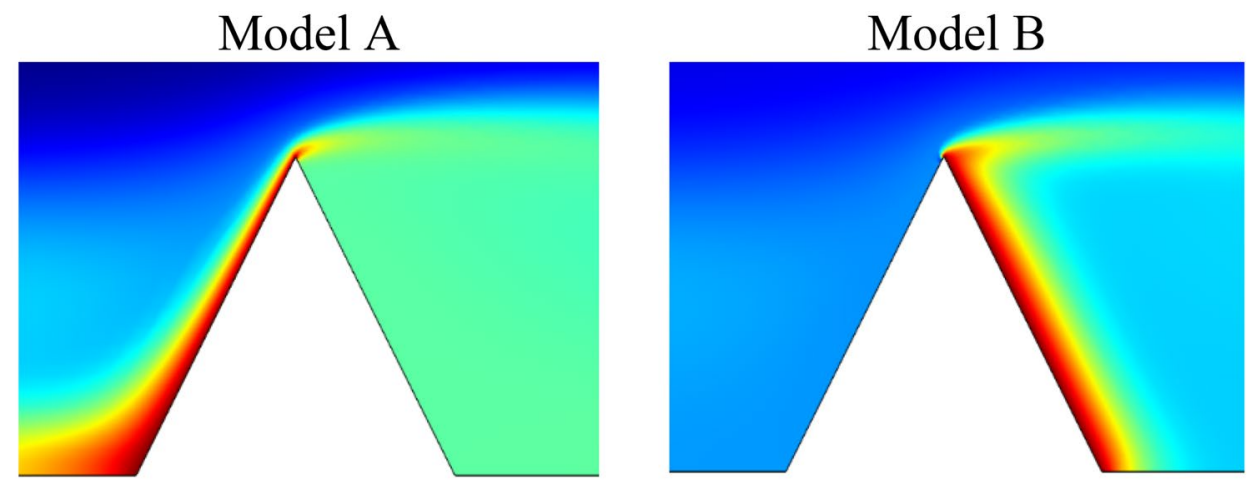

(a)
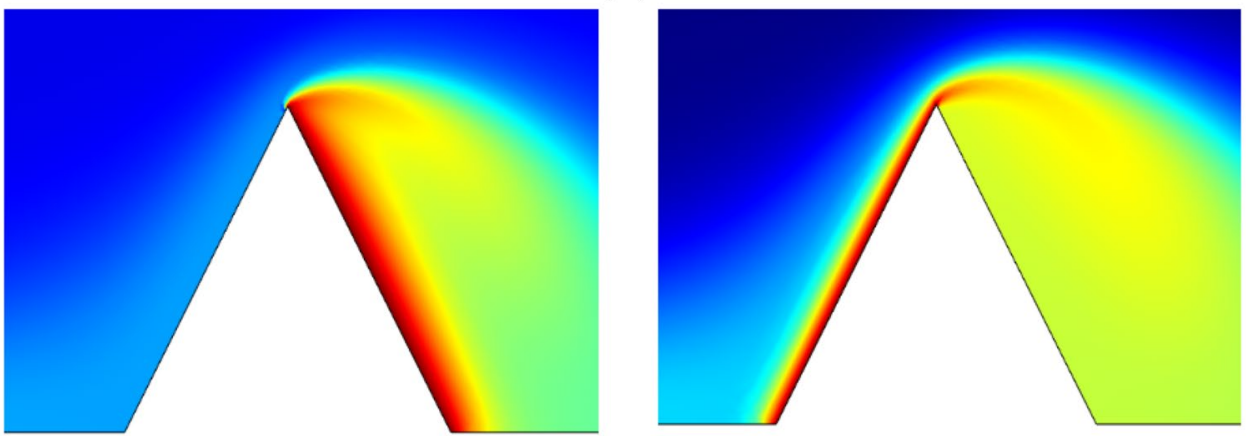

(b)
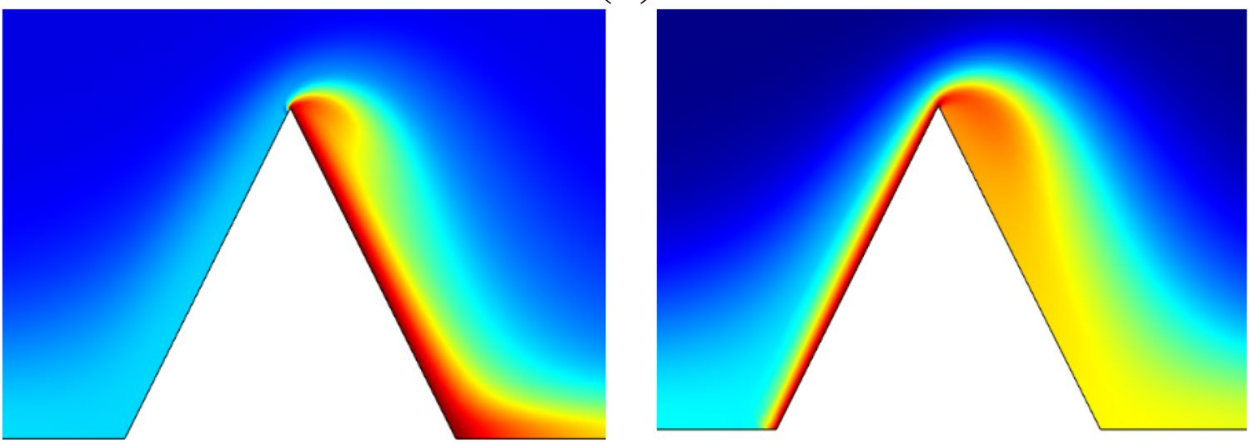

(c)

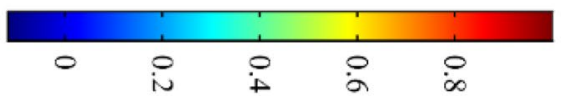

of different nanofluids in microchannels with various types of ribs has been investigated by many researchers. The ribs are embedded on the walls of microchannels to enhance the surface contact between the fluid flow and the walls [2]. On the other hand, the rib-roughened regions cause the velocity to increase, leading to an enhancement in the Nusselt number [16]. The ribs do not allow the thermal boundary layer to form completely. Thus, thermal performance is improved. Since the thermal conductivity of conventional fluid is not too high, nanofluids are employed to increase the thermal conductivity and therefore to improve the heat transfer rate [16]. In the present work, asymmetric boundary conditions were employed on the surfaces of the triangular ribs to evaluate their effect on thermal performance on nanofluid flow in the microchannel. Since previous researchers did not consider assymetric boundary conditions in ribbed microchannels, this effect on the heat transfer rate was evaluated in the present simulations. It was found that the location of heated surface has considerable effect on thermal behavior of the nanofluid. It was concluded that detachment and reattachment of the fluid flow in rib-roughened region is higher for model B. In other words, if nanofluid flow first collides with the insulated surface of the ribs, the tabulator height and friction coefficient $[38,39]$ are smaller than 


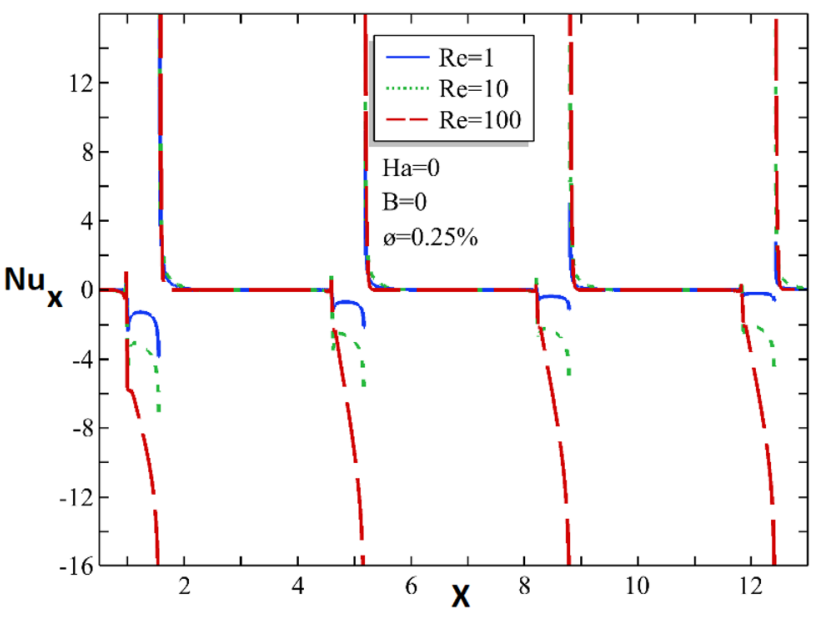

Fig. $11 \mathrm{Nu}_{\mathrm{x}}$ for model $\mathrm{A}$ of ribs at $\varphi=0.0025, \mathrm{~B}=0, \mathrm{Ha}=0$ and different values of $\operatorname{Re}$

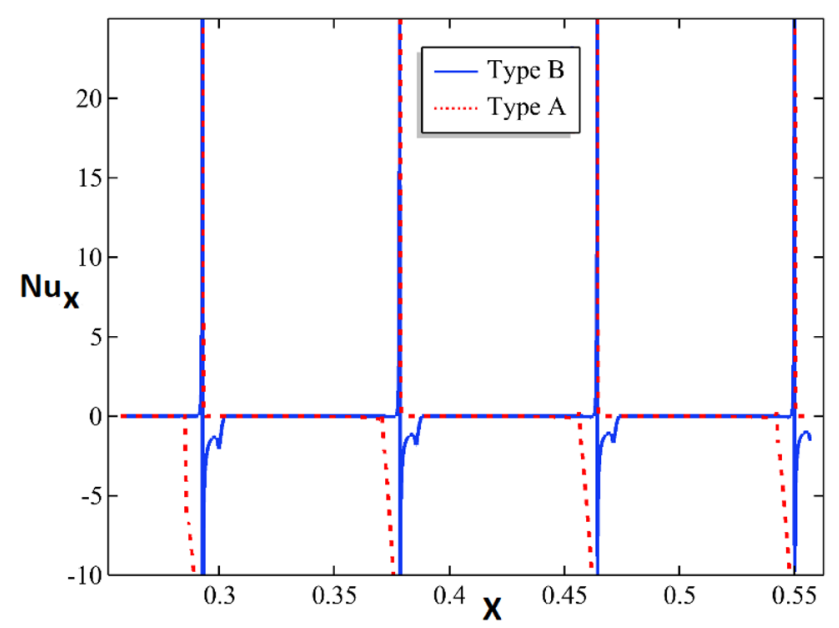

Fig. $12 \mathrm{Nu}_{\mathrm{m}}$ for model $\mathrm{A}$ and model $\mathrm{B}$ of ribs at $\varnothing=0.0025, \mathrm{~B}=0$, $\mathrm{Re}=10$ and $\mathrm{Ha}=0$

that when the fluid flow interacts first with the heated surface of the ribs.

\section{Conclusions}

The present paper investigated forced convection heat transfer of water/FMWCNT nanofluid inside a rectangular microchannel with triangular ribs mounted on the lower wall numerically. Two models of ribs were considered based on the location of constant temperature and insulated surfaces of the ribs. The effect of magnetic field, Re, slip coefficient and $\varphi$ on the velocity and temperature fields were evaluated. The main results were obtained as follows: An increase in Re leads to an increase in the slip

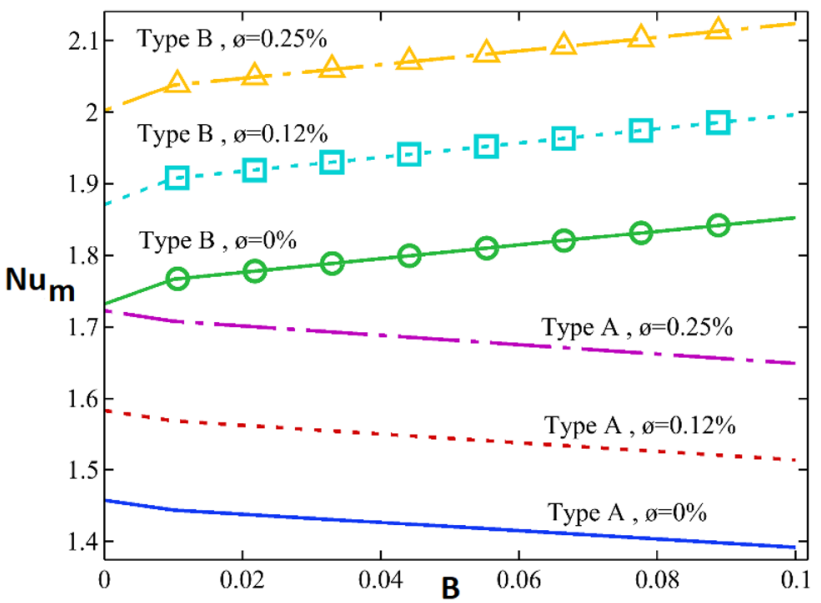

Fig. $13 \mathrm{Nu}_{\mathrm{m}}$ versus slip coefficient for $\mathrm{Ha}=0, \mathrm{Re}=10$ and various volume fractions of nanoparticles

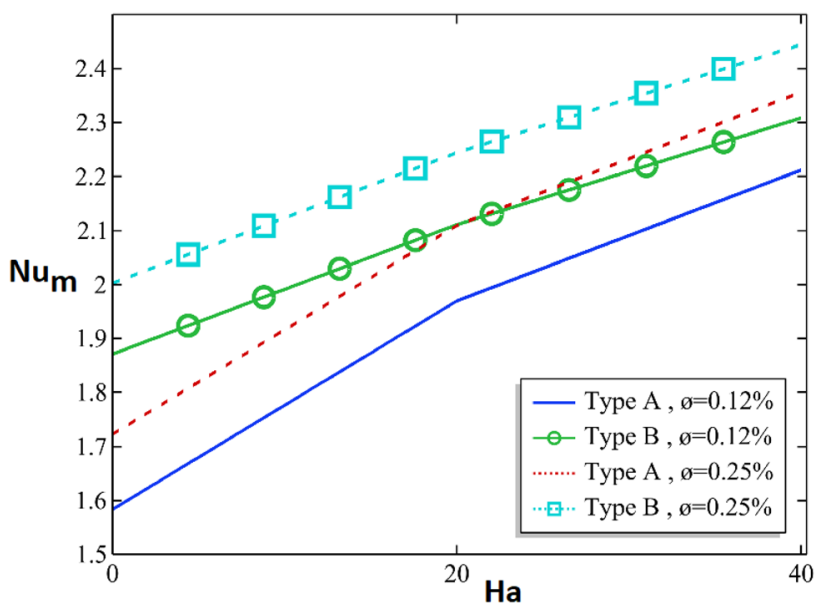

Fig. $14 \mathrm{Nu}_{\mathrm{m}}$ versus $\mathrm{Ha}$ for $\mathrm{B}=0, \mathrm{Re}=10$ and various volume fractions of nanoparticles

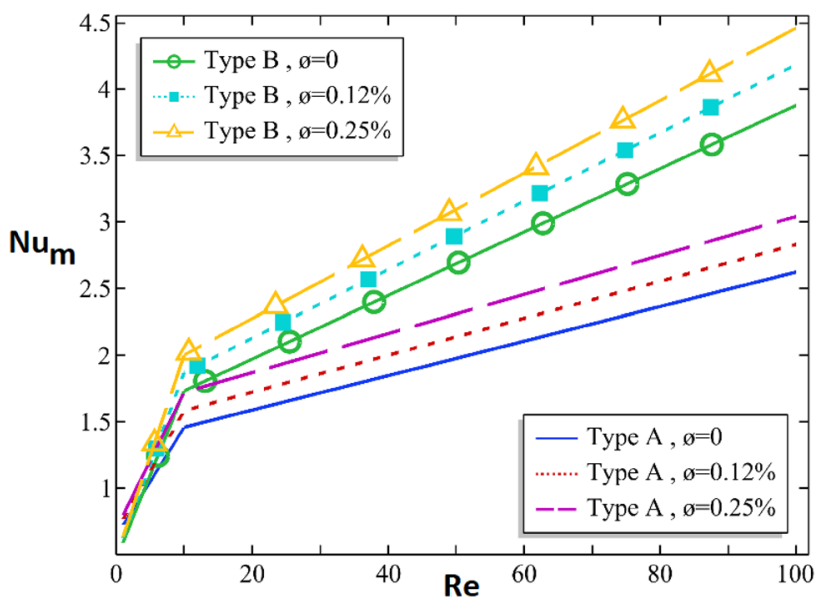

Fig. $15 N u_{m}$ versus $\mathrm{Re}$ in the absence of magnetic field and slip coefficient 
velocity, $\mathrm{Nu}_{\mathrm{x}}$ and $\mathrm{Nu}_{\mathrm{m}}$. As the magnetic field is applied, the Lorentz force is generated in the opposite direction of the nanofluid flow, leading to a reduction in the slip velocity and an enhancement in the accumulation of nanoparticles in the regions near the microchannel walls. Hence, the temperature gradient, $\mathrm{Nu}_{x}$ and $\mathrm{Nu}_{m}$ increase. It was found that $\mathrm{Nu}_{x}$ and $\mathrm{Nu}_{m}$ increase with $\mathrm{Ha}$ and $\varphi$. As $u_{s}$ increases, the heat transfer increases for model $B$ and decreases for model $A$. The enhancement of $\mathrm{Nu}_{\mathrm{m}}$ for model $\mathrm{A}$ is smaller than that for model $\mathrm{B}$ when Re increases.

\section{Compliance with ethical standards}

Conflict of interest All authors declare that they have no conflict of interest.

\section{References}

1. Mokrani O, Bourouga B, Castelain C, Peerhossaini H (2009) Fluid flow and convective heat transfer in flat microchannels. Int J Heat Mass Transf 52:1337-1352

2. Malvandi A, Ganji DD (2015) Effects of nanoparticle migration and asymmetric heating on magnetohydrodynamic forced convection of alumina/water nanofluid in microchannels. Eur J Mech B Fluid 52:169-184

3. Akbarinia A, Abdolzadeh M, Laur R (2011) Critical investigation of heat transfer enhancement using nanofluids in microchannels with slip and non-slip flow regimes. Appl Therm Eng 31:556-565

4. Sepyani M, Shateri A, Bayareh M (2019) Investigating the mixed convection heat transfer of a nanofluid in a square chamber with a rotating blade. J Therm Anal Calorim 135:609-623

5. Bayareh M, Kianfar A, Kasaeipour A (2018) Mixed convection heat transfer of water-alumina nanofluid in an inclined and baffled c-shaped enclosure. J Heat Mass Transf Res 5(2):129-138

6. Shirazi M, Shateri A, Bayareh M (2018) Numerical investigation of mixed convection heat transfer of a nanofluid in a circular enclosure with a rotating inner cylinder. J Therm Anal Calorim 133(2):1061-1073

7. Bayareh M, Hajatzadeh Pordanjani A, Ahmadi Nadooshan A, Shiryan Dehkordi K (2016) Numerical study of the effects of stator boundary conditions and blade geometry on the efficiency of a scraped surface heat exchanger. Appl Therm Eng 113:1426-1436

8. Moghari RM, Akbarinia A, Shariat M, Talebi F, Laur R (2011) Two phase mixed convection $\mathrm{Al}_{2} \mathrm{O}_{3}$-water nanofluid flow in an annulus. Int J Multiph Flow 37:585-595

9. Sheikhzadeh G, Qomi ME, Hajialigol N, Fattahi A (2013) Effect of $\mathrm{Al}_{2} \mathrm{O}_{3}$-water nanofluid on heat transfer and pressure drop in a three-dimensional microchannel. Int J Nano Dimens 3:281-288

10. Tsai T-H, Chein R (2007) Performance analysis of nanofluid-cooled microchannel heat sinks. Int J Heat Fluid Flow 28(5):1013-1026

11. Wen D, Ding Y (2004) Experimental investigation into convective heat transfer of nanofluids at the entrance region under laminar flow conditions. Int J Heat Mass Transf 47(2):5181-5188
12. Jahanbakhshi A, Ahmadi Nadooshan A, Bayareh M (2018) Magnetic field effects on natural convection flow of a non-Newtonian fluid in an L-shaped enclosure. J Therm Anal Calorim 133:1407-1416

13. Sheikholeslami $M$, Shamlooei $M(2017) \mathrm{Fe}_{3} \mathrm{O}_{4}-\mathrm{H}_{2} \mathrm{O}$ nanofluid natural convection in presence of thermal radiation. Int J Hydrogen Energy 42:5708-5718

14. Sheikholeslami M (2018) Influence of magnetic field on Al2O3$\mathrm{H} 2 \mathrm{O}$ nanofluid forced convection heat transfer in a porous lid driven cavity with hot sphere obstacle by means of LBM. J Mol Liq 263:472-488

15. Sheikholeslami M (2018) Solidification of NEPCM under the effect of magnetic field in a porous thermal energy storage enclosure using $\mathrm{CuO}$ nanoparticles. J Mol Liq 263:303-315

16. Afrand M, Karimipour A, Nadooshan AA, Akbari S (2016) The variations of heat transfer and slip velocity of FMWNT-water nano-fluid along the micro-channel in the lack and presence of a magnetic field. Physica E 84:474-481

17. Sheikholeslami M (2017) Magnetic field influence on $\mathrm{CuO}-\mathrm{H}_{2} \mathrm{O}$ nanofluid convective flow in a permeable cavity considering various shapes for nanoparticles. Int J Hydrogen Energy 42:19611-19621

18. Nikkhah Z, Karimipour A, Safaei MR, Forghani-Tehrani $P$, Goodarzi M, Dahari M, Wongwises S (2015) Forced convective heat transfer of water/functionalized multi-walled carbon nanotube nanofluids in a microchannel with oscillating heat flux and slip boundary condition. Int Commun Heat Mass Transf 68:69-77

19. Safaei MR, Ahmadi G, Goodarzi MS, Kamyar A, Kaz SN (2016) Boundary Layer flow and heat transfer of FMWCNT/water nanofluids over a flat plate. Fluids 1(4):31

20. Malvandi A, Ganji DD (2014) Magnetohydrodynamic mixed convective flow of $\mathrm{Al}_{2} \mathrm{O}_{3}$-water nanofluid inside a vertical microtube. J Magn Magn Mater 369:132-141

21. Nemati H, Farhadi M, Sedighi K, Ashorynejad H, Fattahi E (2012) Magnetic field effects on natural convection flow of nanofluid in a rectangular cavity using the Lattice Boltzmann model. Scientica Iranica 19(2):303-310

22. Zhao G, Wang Z, Jian Y (2019) Heat transfer of the MHD nanofluid in porous microtubes under the electrokinetic effects. Int J Heat Mass Transf 130:821-830

23. Vanaki SM, Mohammed H (2015) Numerical study of nanofluid forced convection flow in channels using different shaped transverse ribs. Int Commun Heat Mass Transf 67:176-188

24. Safaei MR, Gooarzi M, Akbari OA, Shadloo MS, Dahari M (2016) Performance evaluation of nanofluids in an inclined ribbed microchannel for electronic cooling applications, Electronics cooling: IntechOpen

25. Heydari A, Akbari O, Safaei MR, Derakhshani M (2018) The effect of attack angle of triangular ribs on heat transfer of nanofluids in a microchannel. J Therm Anal Calorim 131(3):2893-2912

26. Shamsi MR, Akbari OA, Marzban A, Toghraie D, Mashayekhi R (2017) Increasing heat transfer of non-Newtonian nanofluid in rectangular microchannel with triangular ribs. Physica $E$ 93:167-178

27. Shiriny A, Bayareh M, Ahmadi Nadooshan A (2019) Nanofluid flow in a microchannel with inclined cross-flow injection. SN Appl Sci 1:1015

28. Dewan A, Srivastava P (2015) A review of heat transfer enhancement through flow disruption in a microchannel. J Therm Sci 24(3):203-214

29. Habibi A, Shojaei S, Tehrani P, Hassani M, Karimi A (2019) A comparative numerical design of the static and electrostatic micromixers. SN Appl Sci 1:506

30. Usefian A, Bayareh M, Shateri A, Taheri N (2019) Numerical study of electro-osmotic micro-mixing of Newtonian and 
non-Newtonian fluids. J Braz Soc Mech Sci Eng 41:238. https:// doi.org/10.1007/s40430-019-1739-2

31. Usefian A, Bayareh M, Ahmadi Nadooshan A (2018) Rapid mixing of Newtonian and non-Newtonian fluids in a three-dimensional micro-mixer using non-uniform magnetic field. J Heat Mass Transf Res 6(1):55-61

32. Usefian A, Bayareh M (2019) Numerical and experimental study on mixing performance of a novel electro-osmotic micro-mixer. Meccanica 54:1149-1162

33. Pak BC, Cho YI (1998) Hydrodynamic and heat transfer study of dispersed fluids with submicron metallic oxide particles. Exp Heat Transf 11(2):151-170

34. Buongiorno J (2006) Convective transport in nanofluids. J Heat Transf 128:240-250

35. Brinkman HC (1952) The viscosity of concentrated suspensions and solution. J Chem Phys 20:571-581

36. Esmaili Q, Ranjbar AK, Porkhial S (2018) Experimental analysis of heat transfer in ribbed microchannel. Int J Therm Sci 130:140-147
37. Bergles AE (1998) Some perspectives on enhanced heat transfer, second-generation heat transfer technology. J Heat Transf 110:1082-1096

38. Wang X-D, An B, Lin L, Lee D-J (2013) Inverse geometric optimization for geometry of nanofluid-cooled microchannel heat sink. Appl Therm Eng 55:87-94

39. Saha SK (2010) Thermal and friction characteristics of turbulent flow through rectangular and square ducts with transverse ribs and wire-coil inserts. Exp Therm Fluid Sci 34:575-589

Publisher's Note Springer Nature remains neutral with regard to jurisdictional claims in published maps and institutional affiliations. 